\title{
Article
}

||||||||||||||||||||||||||||||||||||||||||||||||

\section{Mössbauer Study of Water-Resistive Conductive Vanadate Glass}

\author{
Isao FURUMOTO*, Shiro KUBUKI** and Tetsuaki NISHIDA *,*** \\ *Graduate School of Advanced Science and Engineering, Kinki University \\ 11-6 Kayanomori, Iizuka-shi, Fukuoka Pref. 820-8555, Japan \\ * * Graduate School of Science and Engineering, Tokyo Metropolitan University \\ 1-1 Minamiosawa, Hachi-oji-shi, Tokyo 192-0397, Japan \\ ***Faculty of Humanity-Oriented Science and Engineering, Kinki University \\ 11-6 Kayanomori, Iizuka-shi, Fukuoka Pref. 820-8555, Japan
}

Received March 5, 2012

\begin{abstract}
Glass transition temperature $\left(T_{g}\right)$ of $20 \mathrm{BaO} \cdot 10 \mathrm{Fe}_{2} \mathrm{O}_{3} \cdot x \mathrm{WO}_{3} \cdot(70-x) \mathrm{V}_{2} \mathrm{O}_{5}$ glasses showed a stepby-step increase from 339 to $470^{\circ} \mathrm{C}$ when $x$ was increased from 0 to 50 , together with a concordant increase in crystallization temperature $\left(T_{c}\right)$ from 406 to $531^{\circ} \mathrm{C}$. Plot of $T_{g}$ against quadrupole splitting $(\Delta)$ of $\mathrm{Fe}^{\mathrm{II}}$ in the Mössbauer spectra yielded a straight line with a slope of $680 \mathrm{~K}\left(\mathrm{~mm} \mathrm{~s}^{-1}\right)^{-1}$. This indicates that $\mathrm{Fe}^{\mathrm{II}}$ atoms constitute distorted $\mathrm{FeO}_{4}$ tetrahedra and play a role of network former in the $3 D$-glass network. Dissolution of vanadium ions from vanadate glass into boiling water was suppressed from 34 to $2 \mathrm{mg} \mathrm{L}^{-1}$ when $x$ was modified from 0 to 50 , reflecting that introduction of $\mathrm{WO}_{3}$ into the $3 D$-network of vanadate glass is effective in the improvement of water resistivity. A gradual decrease of $\Delta$ was observed from 0.82 to $0.76 \mathrm{~mm} \mathrm{~s}^{-1}$ after isothermal annealing of vanadate glass $(x=20)$ at $500^{\circ} \mathrm{C}$ for $240 \mathrm{~min}$, indicating structural relaxation of the glass network, and a marked increase in conductivity $(\sigma)$ from $3.9 \times 10^{-6}$ to $2.1 \times 10^{-3} \mathrm{~S} \mathrm{~cm}^{-1}$ was observed at room temperature.
\end{abstract}

Key Words : Mössbauer spectroscopy, electrical conductivity, semiconducting glass, water resistivity, heat resistivity, structural relaxation

\section{Introduction}

Conduction mechanism of semiconducting vanadate glass was discussed by Mott with a small polaron hopping theory, ${ }^{1)}$ i.e., a step-bystep electron hopping from $\mathrm{V}^{\mathrm{IV}}$ or $\mathrm{V}^{\mathrm{III}}$ to $\mathrm{V}^{\mathrm{V}}$. Semiconducting vanadate glass has attracted much interest in the field of advanced technology like nanotechnology, secondary battery, sensor, etc. Electrical conductivity $(\sigma)$ of asquenched vanadate glass is known to be of the order of $10^{-7}$ to $10^{-5} \mathrm{~S} \mathrm{~cm}^{-12)}$, 3) Electrical conductivity of iron-containing vanadate glass is known to be increased by several orders of magnitude after isothermal annealing at temperatures higher than glass transition temperature $\left(T_{\mathrm{g}}\right)^{3)-5)}$ or crystallization temperature $\left.\left(T_{\mathrm{c}}\right){ }^{6)}{ }^{6}, 7\right)$ Vanadate glass has a lot of industrial applications like cathode-active material electrode for lithium-ion battery, ${ }^{8)}$ electron-emitting needle for ionizer, host material for hyperfine processing with focused ion beam (FIB), sensor, glass lining, etc.

Mössbauer spectroscopy has successfully been utilized for the local structural study of glass and amorphous materials which have interesting physical properties and a lot of applications. Mössbauer spectra provide several im- 
portant chemical and physical information through the Mössbauer parameters of isomer shift $(\delta)$, quadrupole splitting $(\Delta)$, linewidth $(\mathrm{FWHM}: \Gamma)$ and internal magnetic field $\left(H_{\text {int }}\right)$, which are observed as a result of nuclear interaction of Mössbauer atoms with neighboring atoms.

A linear relationship, named $T_{\mathrm{g}}-\boldsymbol{\Delta}$ rule, ${ }^{9}$ was discovered between $T_{\mathrm{g}}$ of inorganic glass and $\Delta$ of $\mathrm{Fe}^{\mathrm{II}}$, being expressed by :

$$
T_{\mathrm{g}}=a \Delta+b .
$$

This experimental rule indicates that $T_{\mathrm{g}}$ of inorganic glasses like oxide glass and halide glass is in proportion to $\Delta$ of $\mathrm{Fe}^{\mathrm{II}}$, reflecting that distortion of network former (NWF)-oxygen polyhedra determines the heat-resistivity of inorganic glasses. Slope " $a$ " of the straight line becomes $680 \mathrm{~K}\left(\mathrm{~mm} \mathrm{~s}^{-1}\right)^{-1}$ when $\mathrm{Fe}^{\mathrm{III}}$ atoms occupy substitutional sites of tetrahedral NWF, while it becomes $260 \mathrm{~K}\left(\mathrm{~mm} \mathrm{~s}^{-1}\right)^{-1}$ when they occupy octahedral NWF sites. ${ }^{10)} T_{\mathrm{g}}-\Delta$ rule is also applicable to a structural study of inorganic glasses in which $\mathrm{Fe}^{\mathrm{III}}$ atoms are present at interstitial network modifier (NWM) sites.' In such case, $T_{\mathrm{g}}$ vs. $\Delta$ plot gives a straight line with a slope " $a$ " of only $35 \mathrm{~K}\left(\mathrm{~mm} \mathrm{~s}^{-1}\right)^{-1}$. It is noteworthy that $T_{\mathrm{g}}-\Delta$ rule is very useful even when we are going to determine the structural role or sites of $\mathrm{Fe}^{\mathrm{II}}$ atoms introduced into unknown glass.

Chemical durability of glass is primarily determined by its composition. This study was carried out in order to improve water-resistivity of barium iron vanadate glass, $20 \mathrm{BaO} \cdot 10$ $\mathrm{Fe}_{2} \mathrm{O}_{3} \cdot 70 \mathrm{~V}_{2} \mathrm{O}_{5}$, so that it could be applied to nanotechnology, secondary battery, sensor, etc. under severe environment: in the hot water and in the atmosphere of high temperature and humidity.

\section{Experimental}

$20 \mathrm{BaO} \cdot 10 \mathrm{Fe}_{2} \mathrm{O}_{3} \cdot x \mathrm{WO}_{3} \cdot(70-x) \mathrm{V}_{2} \mathrm{O}_{5}$ glass was prepared by melting mixture of $\mathrm{BaCO}_{3}, \mathrm{Fe}_{2} \mathrm{O}_{3}, \mathrm{WO}_{3}$ and $\mathrm{V}_{2} \mathrm{O}_{5}$ of guaranteed reagent grade, placed in alumina crucible, at $1200^{\circ} \mathrm{C}$ for $90 \mathrm{~min}$ in electric muffle furnace. Each melt was poured into a stainless mold, and was annealed at a given temperature for 0-240 min. Values of $T_{\mathrm{g}}$ and $T_{\mathrm{c}}$ were determined by DTA conducted at a heating rate of $10 \mathrm{~K} \mathrm{~min}^{-1}$ with a standard of $\alpha-\mathrm{Al}_{2} \mathrm{O}_{3}$. Mössbauer spectra were measured by a constant acceleration method with a ${ }^{57} \mathrm{Co}(\mathrm{Rh})$ source and a reference of $\alpha$-Fe foil, which was also used for calibrating the velocity scale of the spectrometer. For the Mössbauer measurement, each glass powder was diluted with boron nitride $(\mathrm{BN})$.

Electrical conductivity $(\sigma)$ was measured at room temperature by a DC four-probe method with a rectangular glass sample of which each end was coated with silver paste. Copper lead wires were attached to each end with silver-containing $\mathrm{SnO}_{2}$ solder. Electrical resistivity $(R)$ was calculated from the slope of the straight line obtained by plotting the potential against the current. Specific conductivity $(\sigma)$ was calculated with $R$ and size of the glass sample, i.e.,

$$
\sigma=R^{-1} \cdot S^{-1} \cdot l,
$$

in which $S$ is the cross section (in $\mathrm{cm}^{2}$ ) of the glass sample and $l$ the length (in $\mathrm{cm}$ ).

Water-resistivity was estimated by determining the concentration of vanadium, tungsten and iron ions dissolved into boiling water $(15 \mathrm{~mL})$, in which each glass sample $(1.0 \mathrm{~g})$ was immersed for $2 \mathrm{~h}$. Atomic absorption spectroscopy was used for determining the metal 

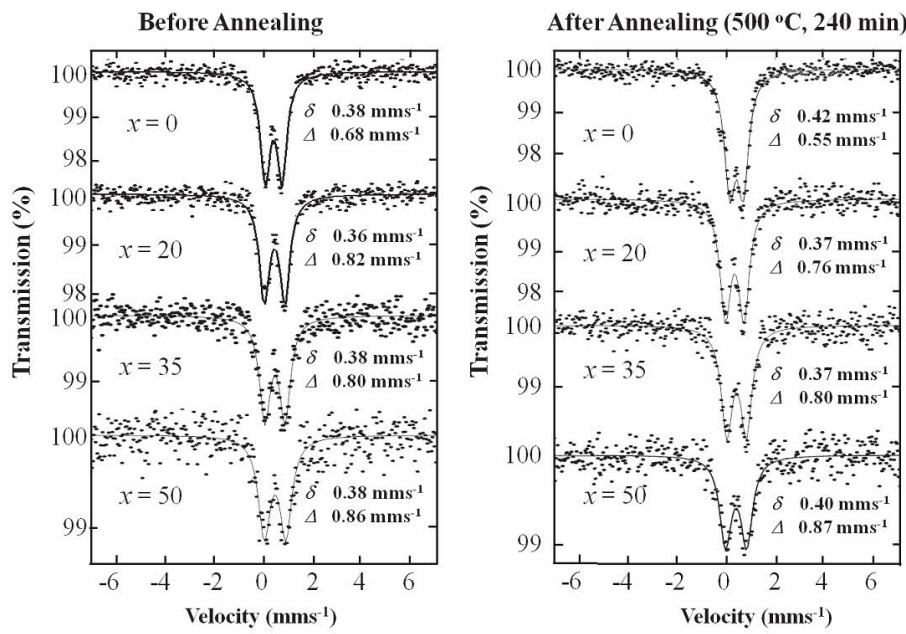

Fig. 1 Mössbauer spectra of $20 \mathrm{BaO} \cdot 10 \mathrm{Fe}_{2} \mathrm{O}_{3} \cdot x \mathrm{WO}_{3} \cdot(70-x) \mathrm{V}_{2} \mathrm{O}_{5}$ glasses measured at room temperature before and after isothermal annealing at $500^{\circ} \mathrm{C}$ for $240 \mathrm{~min}$.

ions in the boiling water before and after the leaching test.

\section{Results and Discussion}

Figure 1 shows Mössbauer spectra of $20 \mathrm{BaO}$. $10 \mathrm{Fe}_{2} \mathrm{O}_{3} \cdot x \mathrm{WO}_{3} \cdot(70-x) \mathrm{V}_{2} \mathrm{O}_{5}$ glasses, measured at room temperature before and after isothermal annealing. Each spectrum was analyzed into one paramagnetic doublet due to distorted $\mathrm{Fe}^{\mathrm{II}} \mathrm{O}_{4}$ tetrahedra. As-quenched $20 \mathrm{BaO}$. $10 \mathrm{Fe}_{2} \mathrm{O}_{3} \cdot 70 \mathrm{~V}_{2} \mathrm{O}_{5}$ glass $(x=0)$ has $\delta$ and $\Delta$ values of $0.38 \pm 0.01$ and $0.68 \pm 0.02 \mathrm{~mm} \mathrm{~s}^{-1}$, respectively. Value of $\Delta$ decreased from $0.68 \pm 0.02$ to $0.55 \pm 0.02 \mathrm{~mm} \mathrm{~s}^{-1}$ after isothermal annealing at $500^{\circ} \mathrm{C}$ for $240 \mathrm{~min}$, while $\delta$ showed a very slight increase from $0.38 \pm 0.01$ to $0.42 \pm 0.01 \mathrm{~mm} \mathrm{~s}^{-1}$.

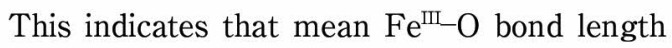
and the coordination number of $\mathrm{Fe}^{\mathrm{II}}$ are scarcely changed by the isothermal annealing.

The decrease of $\Delta$ is ascribed to a decreased distortion or an increased local symmetry of $\mathrm{Fe}^{\mathrm{mI}} \mathrm{O}_{4}$ tetrahedra, as has been observed in tungsten-free barium iron vanadate glasses ${ }^{4)-7 \text { ), }}$ in which structural relaxation of 3D-glass net- work brought about a marked increase in the conductivity, as illustrated in Fig. 2. Distortion of $\mathrm{Fe}^{\mathrm{mI}} \mathrm{O}_{4}$ tetrahedra can be explained in relation to the electric field gradient, $e q$, at the nuclear site of Mössbauer atoms, i.e.,

$$
e q=e q_{\text {val }}+e q \text { lat },
$$

in which $e q_{\mathrm{val}}$ and $e q_{\text {lat }}$ are the electric field gradient caused by valence electrons and neighboring atoms, respectively. Since high-spin $\mathrm{Fe}^{\mathrm{III}}$ has five valence electrons equally occupied five $3 \mathrm{~d}$-orbitals, $e q_{\text {val }}$ can be ignored, and hence $e q$ is equal to $e q$ lat. Hence, we can directly estimate the distortion of $\mathrm{Fe}^{\mathrm{II}} \mathrm{O}_{4}$ tetrahedra from the decrease of $\Delta$ value.

In case of $20 \mathrm{BaO} \cdot 10 \mathrm{Fe}_{2} \mathrm{O}_{3} \cdot x \mathrm{WO}_{3} \cdot(70-$ x) $\mathrm{V}_{2} \mathrm{O}_{5}$ glasses with " $x$ " of 20,35 and 50 , comparable $\delta$ values of $0.36-0.40 \pm 0.01 \mathrm{~mm} \mathrm{~s}^{-1}$ were obtained irrespective of the heat treatment, indicating identical mean $\mathrm{Fe}^{\mathrm{II}}-\mathrm{O}$ bond length. Quadrupole splitting of tungsten-containing vanadate glass with " $x$ " of 20 showed a decrease from $0.82 \pm 0.02$ to $0.76 \pm 0.02 \mathrm{~mm} \mathrm{~s}^{-1}$ after the isothermal annealing conducted at 
$500{ }^{\circ} \mathrm{C}$ for $240 \mathrm{~min}$.

By contrast, isothermal annealing caused no change of $\Delta$ when " $x$ " was $35(\Delta=0.80 \pm 0.02$ $\left.\mathrm{mm} \mathrm{s}^{-1}\right)$ and $50\left(\Delta=0.86-0.87 \pm 0.02 \mathrm{~mm} \mathrm{~s}^{-1}\right)$. Mössbauer spectra shown in Fig. 1 indicate that structural relaxation of glass network is intrinsic of vanadate glass and that introduction of $\mathrm{WO}_{3}$ into vanadate glass suppresses the structural relaxation of $3 \mathrm{D}$-network of the vanadate glass.

Figure 2 depicts a relationship between $\sigma$ of $20 \mathrm{BaO} \cdot 10 \mathrm{Fe}_{2} \mathrm{O}_{3} \cdot 70 \mathrm{~V}_{2} \mathrm{O}_{5}$ glass and $\Delta$ of $\mathrm{Fe}^{\mathrm{III}}$ measured before and after isothermal annealing at temperatures ranging from 350, 370, 400 and $500^{\circ} \mathrm{C}$. Figure 2 indicates that increase in $\sigma$ is observed along with a decrease of $\Delta$ for $\mathrm{Fe}^{\mathrm{III}}$ which directly reflects an increased symmetry of $\mathrm{Fe}^{\mathrm{II}} \mathrm{O}_{4}$ tetrahedra. Figure 3 shows a relationship between $\sigma$ and $\Delta$ of $\mathrm{Fe}^{\mathrm{III}}$ obtained for $20 \mathrm{BaO} \cdot 10 \mathrm{Fe}_{2} \mathrm{O}_{3} \cdot x \mathrm{WO}_{3} \cdot(70-x) \mathrm{V}_{2} \mathrm{O}_{5}$ glasses with " $x$ " of 20 and 35, measured before and after isothermal annealing at 450,500 and $550^{\circ} \mathrm{C}$. Plot for vanadate glass with " $x$ " $=20$ indicates that $\sigma$ is increased along with a decrease of $\Delta$ for $\mathrm{Fe}^{\mathrm{II}}$. This reflects that decreased distortion of $\mathrm{Fe}^{\mathrm{II}} \mathrm{O}_{4}, \mathrm{~V}^{\mathrm{IV}} \mathrm{O}_{4}$ and $\mathrm{V}^{\mathrm{V}} \mathrm{O}_{4}$ tetrahedra causes an increase in the conductivity, as observed in $20 \mathrm{BaO} \cdot 10 \mathrm{Fe}_{2} \mathrm{O}_{3} \cdot 70 \mathrm{~V}_{2} \mathrm{O}_{5}$ glass (Fig. 2). It is noted that isothermal annealing of iron-containing vanadate glass causes a decrease of $\Delta$ for $\mathrm{Fe}^{\mathrm{II}}$ together with a marked decrease in the activation energy $\left(E_{\mathrm{a}}\right)$ for the conduction from 0.37 to $0.13( \pm 0.01) \mathrm{eV} .{ }^{11)}$ Similar decrease of $E_{\mathrm{a}}$ from $0.33( \pm 0.07)$ to $0.11( \pm 0.01) \mathrm{eV}$ was observed in $20 \mathrm{BaO} \cdot 10 \mathrm{Fe}_{2} \mathrm{O}_{3} \cdot x \mathrm{MnO}_{2} \cdot(70-x)$ $\mathrm{V}_{2} \mathrm{O}_{5}$ glasses. ${ }^{12)}$ We can understand from Figs. 2 and 3 that the correlation between $\sigma$ and $\Delta$ becomes weaker when more $\mathrm{V}_{2} \mathrm{O}_{5}$ was replaced by $\mathrm{WO}_{3}$. These results evidently show that the increase of $\sigma$ associated with a decrease in the

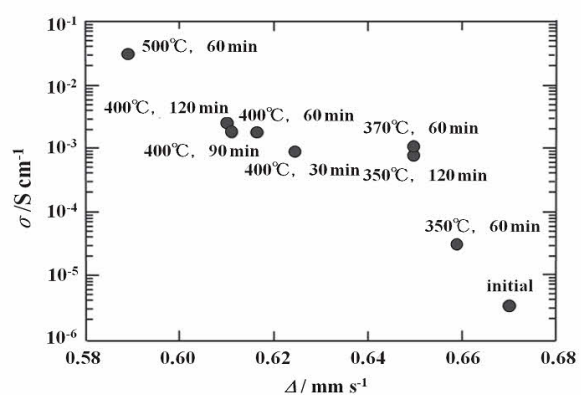

Fig. 2 A relationship between electrical conductivity $(\sigma)$ of $20 \mathrm{BaO} \cdot 10 \mathrm{Fe}_{2} \mathrm{O}_{3}$. $70 \mathrm{~V}_{2} \mathrm{O}_{5}$ glass and $\Delta$ of $\mathrm{Fe}^{\mathrm{III}}$ measured before and after isothermal annealing at different temperatures ranging from 350 to $500^{\circ} \mathrm{C}$.

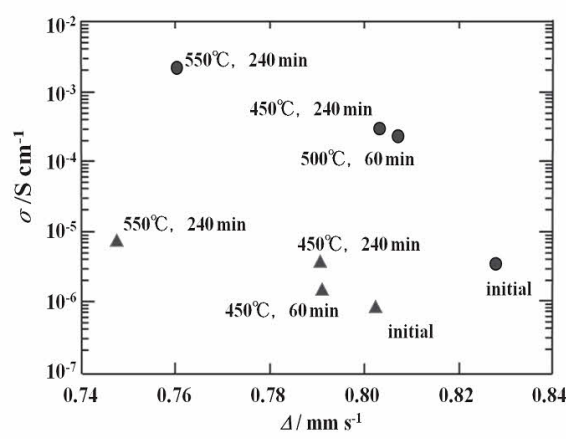

Fig. 3 A relationship between electrical conductivity $(\sigma)$ of $20 \mathrm{BaO} \cdot 10 \mathrm{Fe}_{2} \mathrm{O}_{3}$. $x \mathrm{WO}_{3} \cdot(70-x) \mathrm{V}_{2} \mathrm{O}_{5}$ glasses ( “ $x$ ” $=20$ and 35 ) and $\Delta$ of $\mathrm{Fe}^{\mathrm{III}}$ measured before and after isothermal annealing at 450, 500 and $550^{\circ} \mathrm{C} ; 0:$ : $x "=20, \boldsymbol{\Delta}: " x "=35$.

distortion of $\mathrm{Fe}^{\mathrm{II}} \mathrm{O}_{4}, \mathrm{~V}^{\mathrm{IV}} \mathrm{O}_{4}$ and $\mathrm{V}^{\mathrm{V}} \mathrm{O}_{4}$ tetrahedra is intrinsic of vanadate glass matrix, and that introduction of $\mathrm{WO}_{3}$ causes no essential effect to the conduction mechanism of vanadate glass.

Glass transition temperatures $\left(T_{\mathrm{g}}\right)$ of $20 \mathrm{BaO}$. $10 \mathrm{Fe}_{2} \mathrm{O}_{3} \cdot x \mathrm{WO}_{3} \cdot(70-x) \mathrm{V}_{2} \mathrm{O}_{5}$ glasses with “ $x$ " of $0,20,35$ and 50 are plotted against $\Delta$ of $\mathrm{Fe}^{\mathrm{mI}}$ in Fig. 4, together with corresponding plots obtained earlier for aluminate, gallate, borosilicate and vanadate glasses.' $\mathrm{A}$ linear re- 


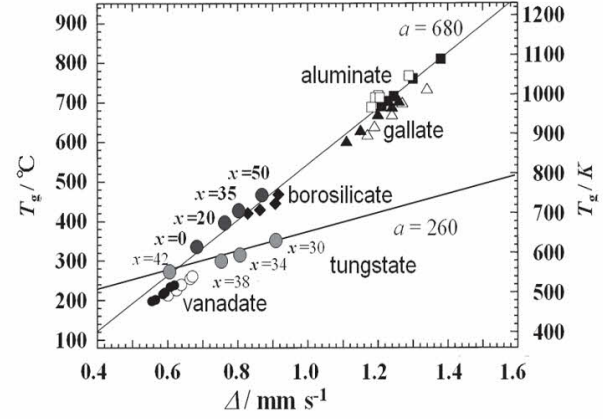

Fig. $4 T_{g}$ vs. $\Delta$ plot for $20 \mathrm{BaO} \cdot 10 \mathrm{Fe}_{2} \mathrm{O}_{3}$. $x \mathrm{WO}_{3} \cdot(70-x) \mathrm{V}_{2} \mathrm{O}_{5}$ glasses with " $x$ " of $0,20,35$ and 50 . Corresponding plot for tungstate glass, $x \mathrm{Na}_{2} \mathrm{O} \cdot \mathrm{Fe}_{2} \mathrm{O}_{3} \cdot(99-$ x) $\mathrm{WO}_{3}$, with a slope of $260 \mathrm{~K}\left(\mathrm{~mm} \mathrm{~s}^{-1}\right)^{-1}$ is given for comparison. ${ }^{10)}$ Plots for alkali vanadate glass $(\odot, \bigcirc)$, borosilicate glass $(\bullet)$, gallate glass $(\boldsymbol{\Delta}, \triangle)$ and aluminate glass $(\square, \square)$ yield a straight line with a "common" slope of $680 \mathrm{~K}(\mathrm{~mm}$ $\left.\mathrm{S}^{-1}\right)^{-1} \cdot \mathbf{9}^{\text {) }}$

lationship is observed in these glasses with an

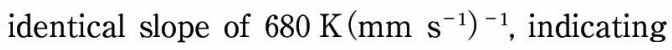
that distorted $\mathrm{Fe}^{\mathrm{III}} \mathrm{O}_{4}$ tetrahedra occupy NFW sites, as do $\mathrm{AlO}_{4}, \mathrm{GaO}_{4}, \mathrm{BO}_{4}, \mathrm{SiO}_{4}$ and $\mathrm{VO}_{4}$ tetrahedra in aluminate, gallate, borosilicate and vanadate glasses. ${ }^{9)}$ In a recent study of 20 $\mathrm{BaO} \cdot 10 \mathrm{Fe}_{2} \mathrm{O}_{3} \cdot x \mathrm{MnO}_{2} \cdot(70-x) \mathrm{V}_{2} \mathrm{O}_{5}$ glasses, ${ }^{12)}$ slope of $707 \mathrm{~K}\left(\mathrm{~mm} \mathrm{~s}^{-1}\right)^{-1}$ was obtained from the straight line. We can evidently exclude another possibility that $\mathrm{Fe}^{\mathrm{II}}$ atoms oc- cupy octahedral NWF sites in $20 \mathrm{BaO} \cdot 10$ $\mathrm{Fe}_{2} \mathrm{O}_{3} \cdot x \mathrm{WO}_{3} \cdot(70-x) \mathrm{V}_{2} \mathrm{O}_{5}$ glasses at the substitutional sites of distorted $\mathrm{WO}_{6}$ octahedra, as earlier observed in $x \mathrm{Na}_{2} \mathrm{O} \cdot \mathrm{Fe}_{2} \mathrm{O}_{3} \cdot(99-x)$ $\mathrm{WO}_{3}$ glasses in which $T_{\mathrm{g}}$ vs. $\Delta$ plot yielded a straight line with a slope of $260 \mathrm{~K}\left(\mathrm{~mm} \mathrm{~s}^{-1}\right)^{-1}{ }^{10)}$ Structural information obtained from $T_{\mathrm{g}}$ vs. $\Delta$ plot is that we can know the local structure of $\mathrm{Fe}^{\mathrm{II}} \mathrm{O}_{4}$ tetrahedra that are connected to $\mathrm{VO}_{4}$ tetrahedra or $\mathrm{VO}_{5}$ pyramids by sharing corner oxygen atoms in the 3D-glass network.

Chemical durability of $20 \mathrm{BaO} \cdot 10 \mathrm{Fe}_{2} \mathrm{O}_{3}$. $x \mathrm{WO}_{3} \cdot(70-x) \mathrm{V}_{2} \mathrm{O}_{5}$ glasses, estimated from a $2 \mathrm{~h}$-leaching test in boiling water, is summarized in Table 1. It is understood from the leaching test that introduction of $\mathrm{WO}_{3}$ into ironcontaining vanadate glass results in an increased water-resistivity, e.g., dissolution of vanadium ions were suppressed from 30 to 11 and $10 \mathrm{mg} \mathrm{L}^{-1}$ when " $x$ " were 20 and 35 , respectively. Higher water-resistivity was achieved in $20 \mathrm{BaO} \cdot 10 \mathrm{Fe}_{2} \mathrm{O}_{3} \cdot 50 \mathrm{WO}_{3} \cdot 20$ $\mathrm{V}_{2} \mathrm{O}_{5}$ glass in which only a few $\mathrm{mg} \mathrm{L}^{-1}$ of vanadium ions were detected after the leaching test. This leaching test suggests that introduction of $20 \mathrm{~mol} \%$ of $\mathrm{WO}_{3}$ is effective in the preparation of vanadate glass with higher water-resistivity, and that $50 \mathrm{~mol} \%$ of $\mathrm{WO}_{3}$ could satisfactorily suppress the dissolution of vanadium ions. It is obvious from Table 1 that dissolution of iron

Table 1 Concentration of metal ions dissolved into boiling water after 2h-leaching

\begin{tabular}{llll}
\hline Composition & $\mathrm{V}$ & $\mathrm{W}$ & $\mathrm{Fe}$ \\
\hline $20 \mathrm{BaO} \cdot 10 \mathrm{Fe}_{2} \mathrm{O}_{3} \cdot 70 \mathrm{~V}_{2} \mathrm{O}_{5}{ }^{*}$ & $30(34)$ & - & $\mathrm{ND}(1)$ \\
\hline $20 \mathrm{BaO} \cdot 10 \mathrm{Fe}_{2} \mathrm{O}_{3} \cdot 20 \mathrm{WO}_{3} \cdot 50 \mathrm{~V}_{2} \mathrm{O}_{5}{ }^{*}$ & $11(21)$ & $1(4)$ & $\mathrm{ND}(\mathrm{ND})$ \\
\hline $20 \mathrm{BaO} \cdot 10 \mathrm{Fe}_{2} \mathrm{O}_{3} \cdot 35 \mathrm{WO}_{3} \cdot 35 \mathrm{~V}_{2} \mathrm{O}_{5}{ }^{*}$ & $10(16)$ & $3(8)$ & $\mathrm{ND}(\mathrm{ND})$ \\
\hline $20 \mathrm{BaO} \cdot 10 \mathrm{Fe}_{2} \mathrm{O}_{3} \cdot 50 \mathrm{WO}_{3} \cdot 20 \mathrm{~V}_{2} \mathrm{O}_{5}{ }^{*}$ & $3(2)$ & $4(8)$ & $\mathrm{ND}(\mathrm{ND})$ \\
\hline
\end{tabular}

*All the samples annealed at $500{ }^{\circ} \mathrm{C}$ for $1 \mathrm{~h}$. Value in parenthesis for non-annealed sample. ND: non-detected. 
was nearly zero, although only a small amount of tungsten ions were detected when $\mathrm{WO}_{3}$ content was 35 or $50 \mathrm{~mol} \%$.

\section{Summary}

Iron(III) atoms constitute distorted $\mathrm{FeO}_{4}$ tetrahedra at substitutional sites of $\mathrm{VO}_{4}$ and $\mathrm{WO}_{4}$ tetrahedra, constituting 3D-network structure of barium iron tungsten vanadate glass. Isothermal annealing at temperatures higher than $T_{\mathrm{c}}$ results in a marked decrease in $\Delta$ due to decreased distortion of $\mathrm{FeO}_{4}$ tetrahedra. This is also the case for $\mathrm{VO}_{4}$ and $\mathrm{WO}_{4}$ tetrahedra since they share corner oxygen atoms with $\mathrm{FeO}_{4}$ tetrahedra. Decrease in the local distortion of 3D-network causes an increase in $\sigma$, which is in proportion to the content of $\mathrm{V}_{2} \mathrm{O}_{5}$. This indicates that the increase in $\sigma$, generally observed together with a structural relaxation of glass network, is intrinsic of vanadate glass. Substitution of $\mathrm{WO}_{3}$ for $\mathrm{V}_{2} \mathrm{O}_{5}$ is effective in the improvement of water-resistivity of conductive barium iron vanadate glass. We can design and prepare new iron-containing conductive vanadate glass with desired conductivity and water-resistivity by regulating the content of $\mathrm{WO}_{3}$ and $\mathrm{V}_{2} \mathrm{O}_{5}$.

\section{References}

1) Mott, N. F., Adv. Phys., 16(61), 49-144(1967)
2) Nishida, T., Ide, H., Takashima, Y., Yagi, T., Tomariguchi, S., Ishizuka, T. and Sakai, A., J . Mater. Sci., 24, 1687-1692 (1989)

3) Nishida, T., Kubota, J., Maeda, Y., Ichikawa, F. and Aomine, T., J. Mater. Chem., 6, 1889-1896 (1996)

4) Nishida, T., Japanese Patent, No. 3854985 (2006)

5) Fukuda, K., Ikeda, A. and Nishida, T., Solid State Phenom., 90-91, 215-220(2003)

6) Nishida, T., Japanese Patent, Tokugan 200699286 (2006) /2008-508645 (2008)

7) Kubuki, S., Sakka, H., Tsuge, K., Homonnay, Z., Sinkó, K., Kuzmann, E., Yasumitsu, H. and Nishida, T., J. Ceram. Soc. Jpn., 115, 776-779 (2007)

8) Nishida, T., Yoshida, Y., Takahashi, Y., Okada, S. and Yamaki, J., J. Radioanal. Nucl. Chem., 275 (2), 417-422 (2008)

9) Nishida, T., Ide, H. and Takashima, Y., Bull. Chem. Soc.Jpn., 63, 548-553(1990)

10) Nishida, T., Suzuki, M., Kubuki, S., Katada, M. and Maeda, Y., J. Non-Cryst. Solids, 194, 23-33 (1996)

11) Nishida, T. and Kubuki, S., Mössbauer Spectroscopy: Applications in Chemistry, Biology, Nanotechnology, Industry and Environment, eds. Sharma, V.K., Klingelhöfer, G. and Nishida, T., Ch. 33, John Wiley, New York (in press)

12) Kubuki, S., Masuda, H., Akiyama, K., Furumoto, I. and Nishida, T., Hyperfine Interact., DOI 10.1007/s 10751-011-0433-2 (2011) 